\title{
Penggunaan Kromoterapi dalam Konseling Untuk Penangangan Kejenuhan Belajar Siswa Pada Era Revolusi Industri 4.0
}

\author{
Reza Tri Rizky ${ }^{1}$, Taufik², Khairani ${ }^{3}$, Frischa Meivilona Yendi', Verlanda Yuca ${ }^{5}$ \\ ${ }^{12345}$ Universitas Negeri Padang \\ *) Correspondence author, e-mail : rezatririzky@gmail.com
}

\begin{abstract}
Perkembangan revolusi industri pada dasarnya membawa permasalahan tertentu yang dapat mengganggu kehidupan siswa terutama di sekolah. Salah satu permasalahan yang dimaksud adalah kejenuhan belajar. Dalam menghadapi hal tersebut maka diperlukan jalan keluar serta alternatif penyelesaian masalah yang tepat dan efisien dalam menghadapi kondisi tersebut. Salah satu bentuk penyelesaian permasalahan tersebut adalah kromoterapi atau terapi warna yang dapat dimanfaatkan dalam pelaksanaan konseling di sekolah.
\end{abstract}

Keywords: Kromoterapi, Kejenuhan Belajar, Revolusi Industri

Article History: Received on 20/05/2019; Revised on 20/06/2019; Accepted on 17/07/2019; Published Online: 21/07/2019. distribution, and reproduction in any medium, provided the original work is properly cited. (C2019 by author.

\section{PENDAHULUAN}

Permasalahan pada dasarnya bersifat mengganggu, terjadi dalam setiap aspek kehidupan dan memerlukan penanganan yang sesegera mungkin (Bimantoro \& Noor, 2012; Siregar, 2013). Pelaksanaan pendidikan salah satunya. Proses pendidikan tentunya tidak akan terlepas dari permasalahan terutama yang terjadi dan dialami oleh siswa sebagai salah satu aspek penting dari pendidikan itu sendiri (Agung, 2010). Permasalahan tersebut hadir dan berkembang pada diri siswa yang awalnya bersifat sederhana menjadi lebih kompleks. Perkembangan kondisi permasalahan tersebut terjadi dan mengikuti perkembangan zaman (Wijaya, Sudjimat, \& Nyoto, 2016). Triyono (2018) menjelaskan bahwa perkembangan teknologi dan informasi yang terjadi pada era revolusi industri juga melahirkan permasalahan baru pada diri siswa maupun peserta didik dimana sebelumnya permasalahan yang dihadapi oleh siswa hanya berkisar pada bidang pribadi, sosial, belajar dan karir. Sekarang keempat bidang permasalahan tersebut juga dipengaruhi oleh perkembangan teknologi dan informasi yang berkembang sangat cepat.

Akibat dari berkembangnya zaman ini, sistem pendidikan menjadi berubah secara drastis dimana manusia dituntut agar dapat bersaing dan mampu memegang peranan penting dalam perkembangan bangsa itu sendiri (Darmayanti, Setiani \& Oetojo, 2007). Sebab perubahan sitem yang terjadi ini, standar dari pendidikan pun memperoleh peningkatan dalam rangka percepatan perkembangan pengetahuan dan keilmuan untuk seluruh warga dunia dan Indonesia pada umumnya (Saefudin, 2010). Tanpa disadari, 
kondisi ini menjadi beban bagi pelajar Indonesia. Berbagai permasalahan timbul dimana salah satunya adalah kejenuhan belajar akibat kecemasan dari standar atau patokan yang terlalu tinggi dan tidak sesuainya standar tersebut dengan kondisi siswa (Syah, 2015; Nulaila, 2011). Kejenuhan belajar ini dapat berakibat pada keseluruhan aspek kehidupan siswa.

Permasalahan ini tentunya harus memperoleh perhatian terutama bagi aspekaspek pelaksana pendidikan lainnya. Dalam hal ini, tentunya sudah menjadi kewajaran bagi konselor atau guru bimbingan dan konseling sebagai bagian integral dari pendidikan membantu mengentaskan permasalahan kejenuhan belajar siswa (Sodik, 2016). Salah satu layanan yang dapat diberikan adalah konseling individual. Dimana konseling individual adalah layanan bimbingan dan konseling yang memungkinkan peserta didik atau konseli mendapatkan layanan langsung tatap muka (secara perorangan) dengan guru pembimbing dalam rangka pembahasan pengentasan masalah pribadi yang di derita konseli (Helen, 2005). Namun seiring berjalannya waktu, konseling dirasa kurang cukup dalam memenuhi kebutuhan klien terutama siswa dalam rangka pengentasan permasalahan yang terjadi pada dirinya (Damayanti \& Aeni, 2016; Ramdani, 2017; Rofiq, 2018).

Konselor dituntut memiliki pendekatan penanganan permasalahan yang mampu menjadi jalan keluar bagi masalah serta aplikatif dalam menangani permasalahan tersebut (Fitriani \& Rohman, 2016). Salah satu alternatif penanganan yang dapat bermanfaat, aplikatif dan tidak memerlukan waktu yang lama dalam menggunakannya adalah kromoterapi (Aysha, 2016; Benchea, Babusca, \& Morariu, 2015). Penggunaan kromoterapi pada dasarnya telah lama ada dan berkembang sebagai salah satu jalan pengobatan dan penyembuhan baik fisik maupun mental (Wills, 2016).

Penyembuhan mental melalui kromoterapi memanfaatkan beberapa warna yang dapat melambangkan kondisi patologis yang terjadi pada individu $(9,839,762,2017)$. Penanganan kondisi gangguan psikologis dengan kromoterapi ini tidak hanya untuk skala berat namun juga dapat diterapkan pada klien-klien yang mengalami masalah psikologis pada semua aspek kehidupan manusia dimana salah satunya permasalahan pendidikan yang sering dialami oleh peserta didik (Jalili, Nazari, \& Sefidi, 2016).

Dimana kromoterapi ini dapat digunakan pada tahap pembinaan konseling individual setelah konselor memahami dengan baik kondisi yang dialami oleh kliennya.

\section{Sejarah Kromoterapi}

Terapi warna atau kromoterapi pada dasarnya merupakan jenis terapi yang telah lama berkembang (O'Connor, 2011). Warna telah diidentifikasi sebagai obat sejak 2000 tahun sebelum masehi. Masyarakat pada era itu tidak memiliki fakta ilmiah mengenai warna sebagai media penyembuhan namun mereka meyakini bahwa warna dapat memberikan kesembuhan terhadap penyakit yang mereka alami (Azeemi \& Raza, 2005).

Mitologi Mesir kuno menjelaskan bahwa kromoterapi ditemukan oleh dewa Thot (Peschel \& Peschel, 1988; Veiga, 2009) dalam ritualnya, orang-orang Mesir kuno dan Yunani menggunakan mineral berwarna, batu dan kristal sebagai pewarna dalam pengobatan yang mereka lakukan (Oumeish, 1998). Warna juga dianggap berperan secara 
intrinsik dalam mengembalikan keseimbangan, pembuatan minyak dan salep yang digunakan untuk pengobatan (Azeemi \& Raza, 2005).

Kromoterapi sendiri berawal dari Phototerapi atau yang dikenal dengan terapi cahaya (Azeemi \& Raza, 2005). Terapi ini di aplikasikan di Mesir, Yunani, Cina dan India. Orang mesir memanfaatkan warna sebagai media penyembuhannya. Mereka biasa menggunakan warna-warna primer sebagai penyembuhan seperti warna biru, merah dan kuning (Ouseley, 1976).

Avicenna merupakan tokoh yang terkenal dalam praktek kromoterapi (Azeemi, 2009). Dia membuat warna sebagai alat yang penting dalam melakukan diagnosis dan juga perawatan terhadap kliennya (Fadliyah, 2012; Graham, 1998). Menurutnya, warna merupakan gejala yang dapat diobservasi dengan baik (Azeemi \& Raza, 2005). Dia juga mengembangkan diagram yang berhubungan dengan kondisi fisik dan temperatur pada diri seseorang (Azeemi \& Raza, 2005).

\section{Kromoterapi}

Kromoterapi merupakan metode penyembuhan yang menggunakan warna sebagai media utama dalam menangani penyakit yang terjadi pada individu (Withrow, 2004). Kromoterapi memanfaatkan beragam warna dan juga cahaya dalam menyeimbangkan energi dalam tubuh seseorang yang mengalami gangguan tertentu dalam aspek- aspek tertentu seperti emosional, fisik, mental, dan juga spiritual (Liberman, 1990). Beragam warna yang ada pada dasarnya mampu menciptakan rasa kesatuan dan keselarasan yang mempu menunjang kondisi psikologis dan juga psikis individu. (Prasetya \& Adiwoso, 2007). Kromoterapi dapat dilaksanakan dalam beberapa bentuk. Harini (2013) menjelaskan bahwa terdapat beberapa bentuk pelaksanaan dan penggunaan dari kromoterapi ini. Beberapa bentuk tersebut sebagai berikut:

\section{Pernapasan Warna}

Merupakan teknik bernafas dengan membayangkan sewaktu menghirup dan menghembuskan nafas dengan warna-warna tertentu. Klien diminta membayangkan warna yang dapat membuat dirinya tenang dan membayangkan warna yang melambangkan emosi negatif pada dirinya. Saat menghirup nafas, klien diminta untuk membayangkan warna yang disukai masuk kedalam dirinya sedangkan ketika menghembuskan nafas, maka klien diminta membayangkan warna yang tidak disukai keluar dari dirinya.

\section{Meditasi Warna}

Proses terapi yang dilakukan dengan cara membayangkan atau berimajinasi untuk memusatkan perhatian pada objek tertentu yang bersifat citraan/visual, yang mengandung warna-warna, sehingga dapat memberikan efek relaksasi pada tubuh (Mita \& Jakti, 2014).

\section{Air Solarisasi}

Yakni dengan menggunakan botol maupun gelas atau air dengan warna-warna tertentu, kemudian air tersebut diminum. 
64 Penggunaan Kromoterapi dalam Konseling Untuk Penanganan Kejenuhan Belajar Siswa Pada Era Revolusi Industri 4.0

\section{Aurasoma}

Teknik ini menggunakan botol-botol kecil yang berisi lapisan warna dari minyak esensial dan ekstrak tumbuhan (Dalichow \& Both, 1996).

\section{Warna Kain Sutra}

Teknik terapi warna yang menggunakan kain sutra yang dipakaikan ke tubuh pasien untuk digunakan dalam waktu tertentu.

\section{Kejenuhan Belajar}

Syah (2015) menjelaskan bahwa kejenuhan belajar dalam bahasa psikologi dikenal dengan learning plateau atau plateau. Kejenuhan belajar sendiri merupakan rentang waktu tertentu yang digunakan untuk belajar atau mengerjakan tugas belajar namun tidak kunjung membuahkan hasil.

Senada dengan hal tersebut, Corey (Muna, 2016) juga menjelaskan bahwa kejenuhan belajar sebagai suatu keadaan kelelahan fisik, mental, sikap dan emosi individu karena keterlibatan yang intensif dengan tugas dalam jangka waktu yang panjang.

Serupa dengan pendapat sebelumnya, Pines \& Aronson (Jatmiko, 2016) juga menjelaskan bahwa kejenuhan belajar merupakan kondisi emosional ketika seseorang merasa lelah secara mental maupun fisik sebagai akibat tuntutan tugas belajar yang meningkat. Hakim (2005) juga menjelaskan bahwa kejenuhan belajar adalah suatu kondisi mental seseorang saat mengalami rasa bosan dan lelah sehingga mengakibatkan timbulnya rasa enggan, lesu, tidak bersemangat melakukan aktivitas belajar.

Sehingga dapat dipahami bahwa kejenuhan belajar adalah kondisi lelah mbaik secara fisik maupun mental dalam rentang waktu tertentu yang digunakan untuk belajar atau mengerjakan tugas belajar namun tidak kunjung membuahkan hasil tertentu.

\section{Penyebab Kejenuhan Belajar}

Schaufeli \& Enzman (Vitasari, 2016) juga menjelaskan bahwa kejenuhan belajar pada dasarnya disebabkan oleh kelelahan emosi (kemampuan mengendalikan diri dan kecemasan), kehilangan motivasi (kehilangan semangat, kehilangan idealisme, kecewa, pengunduran diri dari lingkungan, kebosanan dan demoralisasi) dan kelelahan kognitif (ketidakmampuan untuk berkonsentrasi, tidak dapat mengerjakan tugas-tugas yang kompleks, kesepian dan penurunan daya tahan dalam menghadapi frustasi yang dirasakan).

Kejenuhan belajar juga dapat disebabkan karena waktu belajar yang terlalu padat (Wahyuni, 2018). Selain itu, Harahap (2017) juga menjelaskan beberapa faktor yang menyebabkan kejenuhan belajar seperti: (1) Subjek studi kurang diminati, (2) Ruangan atau lingkungan dalam belajar kurang nyaman, (3) Kecemasan terhadap dampak negatif yang ditimbulkan oleh keletihan itu sendiri, (4) Kecemasan terhadap standar / patokan keberhasilan bidang- bidang studi tertentu yang dianggap terlalu tinggi (5) Berada di tengah-tengah situasi kompetitif yang ketat dan menuntut lebih banyak kerja intelek yang berat, dan (6) Model pebelajaran yang membosankan dan memerlukan inovasi 
Dari kondisi tersebut dapat dipahami bahwa penyebab dari kejenuhan belajar cukup beragam. Namun kondisi yang terjadi umumnya disebabkan oleh kondisi dari individu yang mengalami kelelahan ataupun keletihan dari segi fisik dan mental.

\section{Akibat Kejenuhan Belajar}

Kejenuhan belajar tentunya akan berakibat buruk kepada aktifitas belajar mahasiswa. Hamzah, Sugiharto \& Tadjri (2017) menjelaskan beberapa akibat dari kejenuhan belajar seperti mudah tersinggung, tidak masuk kedalam kegiatan belajar, bosan dalam kegiatan belajar, tidak fokus dan kurang berkonsentrasi dalam mengerjakan tugas, prestasi akademik menurun. Selanjutnya Muna (2016) juga menjelaskan beberapa kondisi yang menjadi akibat dari kejenuhan belajar itu sendiri. Beberapa akibat tersebut sebagai berikut: (1) Mudah menyerah, lesu, lelah dan tak bergairah dalam belajar, (2) Tidak semangat belajar, (3) Merasa energinya terkuras habis tanpa mendapatkan hal yang penting untuk dirinya, (4) Mudah putus asa dan frustasi, (5) Tidak nyaman berada di dalam kelas maupun mengikuti aktivitas belajar, (6) Bolos, (7) Marah- marah, (8) Tidak mengerjakan tugas, (9) Berpikiran negatif terhadap pengajar, (10) Kehilangan ketertarikan terhadap mata pelajaran, (11) Stress, (12) Tertekan, dan (13) Kurang percaya diri.

Dari hal ini dapat dipahami bahwa pada dasarnya kejenuhan belajar dapat berakibat negative pada proses belajar dimana akibat ini timbul tidak hanya berkaitan dengan awal proses belajar tersebut namun juga berkaitan dari awal proses belajar hingga akhir dari proses belajar itu sendiri.

\section{Kromoterapi dalam Konseling untuk Menangani Kejenuhan Belajar Siswa di Era Revolusi Industri 4.0}

Peningkatan standar pendidikan dalam rangka percepatan perkembangan pengetahuan dan keilmuan bagi individu diperparah dengan karakteristik siswa dari generasi yang tinggal di era revolusi industri itu sendiri. Generasi tersebut dikenal dengan generasi Z. Susana (2018) menjelaskan bahwa kalau generasi X dan Y berhadapan dengan isu workaholic, gaya hidup anak-anak generasi $\mathrm{Z}$ nantinya akan diwarnai sikap speedaholic (segala-galanya diukur dengan kecepatan, siapa cepat dia dapat) dan winaholic (berlomba-lomba mengalahkan lawan) dan persaingan memburu karier. Dalam hal ini, kecepatan menentukan individu dalam mencapai suatu kesuksesan.

Individu yang tidak mampu menyesuaikan diri akan merasakan kecemasan dan menimbulkan kejenuhan dalam proses pendidikan dan belajar yang dihadapinya (Azharghany, 2019 ; Syah, 2015). Tentunya kondisi ini akan menimbulkan dampak negatif pada diri siswa. Dalam menghadapi kondisi tersebut, konselor sebagai bagian penting dari sistem pendidikan itu sendiri diharapkan mampu berperan dalam menangani kondisi yang terjadi pada siswa. Bantuan yang dapat diberikan salah satunya adalah konseling terutama konseling individual yang dapat dilaksanakan langsung kepada siswa yang bermasalah.

Konselor juga dituntut memiliki pemahaman yang baik dan memiliki alternatif jalan keluar penyelesaian permasalahan yang dihadapi siswa. Salah satunya mengadaptasi terapi dalam kegiatan konseling yang dilaksanakan. Salah satu terapi sederhana yang aplikatif tentunya adalah kromoterapi. 
Pelaksanaan kromoterapi tepat dilaksanakan terutama berkenaan dengan permasalahan stress, tekanan dan juga kecemasan (Aysha, 2016). Sehingga dari hal tersebut dapat dipahami bahwa kromoterapi tersebut juga dapat membantu siswa mengatasi kejenuhan belajar yang dialaminya karena pada dasarnya kejenuhan belajar tersebut timbul disebabkan oleh rasa cemas dari sistem dan standar pendidikan yang terus meningkat dan dirasa kurang sesuai dengan kemampunnya sendiri (Aysha, 2016; Syah, 2015; Liberman, 1990).

\section{KESIMPULAN}

Kejenuhan belajar merupakan hasil dari kecemasan akibat peningkatan standar pendidikan yang tinggi dan tidak diiringi dengan keseimbangan antara standar dan kemampuan siswa. Kondisi ini diperparah dengan karakteristik dari generasi $\mathrm{Z}$ yang menginginkan semuanya menjadi serba capat. Dalam hal ini konselor dapat mengambil peran terutama untuk mengatasi permasalahan kejenuhan belajar dengan menggunakan kromoterapi sebagai alternatif penanganan yang dapat diterapkan pada layanan konseling individual.

Pengembangan keilmuan, pengetahuan dan memperkaya pendekatan serta alternative penyelesaian permasalahan yang dihadapi siswa tentunya menjadi tantangan bagi konselor agar dapat terus berperan aktif dalam mendukung peran bimbingan konseling yang menjadi bagian integral dari pendidikan itu sendiri.

\section{REFERENCES}

Agung, I. (2010). Perspektif Multidimensional Pendidikan Pembangunan Berkelanjutan: Pemikiran Awal Konsep dan Penerapan. Jurnal Pendidikan dan Kebudayaan, 16(4), 453-468.

Aysha, K. (2016). Terapi Warna Untuk Mengurangi Kecemasan Pada Remaja yang Hamil Di Luar Nikah. Skripsi. Malang: UMM. http://eprints.umm.ac.id/34421/1/jiptummpp-gdl-kafiyatula-45630-1-skripsi-a.pdf

Azeemi, S., Iram, H., Younas, Q. and Azeemi, A. (2018) Effect of Blue Colour (453 nm Visible Range Radiation) on Anxiety in College Students. Chinese Medicine , 9, 1-6.

Azeemi, S. T. Y. (2009). A Quantitative Study On Chromotherapy. Disertation. Pakistan: University of Balochistan Quetta. http://prr.hec.gov.pk/jspui/handle/123456789//3637.

Azeemi, S. T. Y., \& Raza, S. M. (2005). A Critical Analysis of Chromotherapy and Its Scientific Evolution, 2(4), 481-488. https://doi.org/10.1093/ecam/neh137.

Azharghany, R. (2019). Pesantren Menghadapi Era Otomasi ( Analisis Aktualisasi Nilai dan Tradisi Pesantren Dalam Menghadapi Revolusi Industri 4.0), II, 34-50.

Benchea, A., Babusca, D., \& Morariu, M. (2015). Color in Alternative Therapy. Fizică. Şi. Tehnică, Fizică. şi. 50(1), 50- 61.

Berg, O., \& Rosse, E. (2017). 9,839,762. Washington, DC.

Bimantoro, W., \& Noor, C. (2012). Pengaruh Stres Kerja Terhadap Kinerja Karyawan Di PT Tonga Tiur Putra. Ekonomi, 321(3).

Dalichow, I., \& Both, M. (1996). Aura Soma. California: Hay House, Inc.

Damayanti, R., \& Aeni, T. (2016). Efektivitas Konseling Behavioral Dengan Teknik Modeling Untuk Mengatasi Perilaku Agresif Pada Peserta Didik Smp Negeri 07 
Bandar Lampung Behavioral. Konseli: Jurnal Bimbingan Dan Konseling, 3(1), 1-10.

Darmayanti, T., Setiani, M. Y., \& Oetojo, B. (2007). E-learning pada pendidikan jarak jauh: konsep yang mengubah metode pembelajaran di perguruan tinggi di Indonesia. Jurnal Pendidikan Terbuka dan Jarak Jauh, 8(2), 99-113.

Fadliyah, F. (2012). Warna dalam Al-Qur'an (Kajian Tematik). Skripsi. IAIN Walisongo. http://eprints.walisongo.ac.id/id/eprint/316.

Fitriani, H., \& Rohman, R. Y. (2016). Pengaruh Konseling Terhadap Kecemasan Remaja Putri yang Mengalami Menarche. Jurnal Ilmu Keperawatan, IV(2).

Graham, H. (1998). Discover Colour therapy. USA: Ulysses Press.

Hakim, T. (2005). Belajar Secara Efektif. Jakarta: Puspa Swara.

Hamzah, H., Sugiharto, D. Y. P., \& Tadjri, I. (2017). Efektifitas Konseling Kelompok dengan Teknik Relaksasi Religius untuk Mengurangi Kejenuhan Belajar Mahasiswa. Jurnal Bimbingan Konseling, 6(1), 7-12.

Harahap. J. 2017. “Analisis Faktor-Faktor Penyebab Kejenuhan Belajar Siswa dalam Mata Pelajaran IPS Kelas VIII D SMP Negeri 7 Muaro Jambi". Skripsi. Program Studi Pendidikan Ekonomi. Jurusan PIPS FKIP Universitas Jambi. http://repository.unja.ac.id/2942/1/ARTIKEL\%20ILMIAH.pdf.

Harini, N. (2013). Terapi Warna Untuk Mengurangi Kecemasan. Jurnal Ilmiah Psikologi Terapan, 1(2), 291-303.

Hellen. (2005). Bimbingan dan Konseling . Jakarta: Quantum Teaching.

Ifdil, I., Fadli, R. P., Zola, N., Erwinda, L., Sari, A., Churnia, E., ... \& Ardi, Z. (2019). Chromotherapy: An alternative treatment for mathematics anxiety among elementary school students. In Journal of Physics: Conference Series (Vol. 1175, No. 1, p. 012183). IOP Publishing.

Jalili, T., Nazari, L., \& Sefidi, P. (2016). Article The Survey Of The Color And Light Psychological Effects In Iranian Traditional Architecture ( CASE STUDY: TABATABA ' EES HOUSE ), 7, 469-483.

Jatmiko, R. B. (2016). Perbedaan Tingkat Burnout Belajar Siswa Laki-laki dan Perempuan Kelas VIII di SMP Negeri 3 Pedan. Jurnal Riset Mahasiswa Bimbingan Dan Konseling, 5(2), 11- 19.

Liberman, J. (1990). Light: Medicine of the Future: How We Can Use It to Heal Ourselves Now. USA: Inner Traditions/Bear \& Co.

Mita, P., \& Jakti, R. A. D. R. I. K. (2014). Warna Dingin Si Pemberi Nyaman. Humaniora, $5(1)$.

Muna, N. R. (2016). Efektifitas teknik Self Regulation Learning dalam Mereduksi Tingkat Kejenuhan Belajar Siswa di SMA Insan Cendekia Sekarkemuning Cirebon. Holistik, 14(2), 57- 78.

Nurlaila, S. (2011). Pelatihan efikasi diri untuk menurunkan kecemasan pada siswa-siswi yang akan menghadapi ujian akhir nasional. GUIDENA: Jurnal Ilmu Pendidikan, Psikologi, Bimbingan dan Konseling, 1(1), 1-22.

O'Connor, Z. (2011). Colour Psychology and Colour Therapy: Caveat emptor. Color Research \& Application, 36(3), 229-234.

Oumeish, O. Y. (1998). The Philosophical, Cultural, and Historical Aspects of Complementary, Alternative, Unconventional, and Integrative Medicine in The Old World. Archives of Dermatology,134(11), 1373-1386. 
Ouseley, S. G. (1976). The Power of The Rays. Health Research Books. USA: WD Gan. Inc.

Peschel, R. E., \& Peschel, E. R. (1988). Medical Miracles From a Physician-Scientist's Viewpoint. Perspectives in Biology and Medicine, 31(3), 391-404.

Prasetya, R. D., \& Adiwoso, N. (2007). Pengaruh Komposisi Warna Pada Ruang Kerja Terhadap Stres Kerja,1, 7-16.

Ramdani, A. (2017). Peran Guru Al Islam Kemuhammadiyahan (Ismuba) Dalam Mengatasi Agresivitas Siswa Sma Muhammadiyah 3 Yogyakarta. UMY.

Rofiq, A. (2018). Upaya Tokoh Agama Dalam Menangani Remaja Berperilaku Agresif di Desa Wates Kecamatan Undaan Kabupaten Kudus, (121111107).

Saefudin, A. (2010). Pendekatan Total Quality Manajement (TQM) Dalam Globalisasi Pendidikan. Jurnal MANAJERIAL, 9(2), 91-96.

Siregar, B. G. (2013). Solusi Dalam Menghadapi Permasalahan Remaja. Hikmah, 7(1), 101-114.

Sodik, A. (2016). Konseling Sebagai Suatu Sistem Pendidikan Sekolah. HISBAH: Jurnal Bimbingan Konseling dan Dakwah Islam, 13(1), 1-17.

Susana, T. (2018). Kesetiaan Pada Panggilan Di Era Digital, 55-78.

Syah, M. (2015). Psikologi belajar. Jakarta: Rajawali Press.

Triyono. (2018). Mereka-reka Strategi Bimbingan dan Konseling Dalam Era Disrupsi/Revolusi Industri 4.0 Bagi Generasi Z, 19-22.

Veiga, P. (2009). Health and Medicine In Ancient Egypt; Magic and Science. Disertation. http://hdl.handle.net/10919/71526.

Vitasari, I. 2016. Kejenuhan Belajar Ditinjau dari Kesepian dan Kontrol Diri Siswa Kelas XI SMAN 9 Yogyakarta. E-Journal Bimbingan dan Konseling. 7.

Wahyuni, E. D. (2018). Faktor-Faktor Penyebab Tingkat Kejenuhan Belajar Pendidikan Agama Islam (Pai) Pada Jurusan PGSD di Universitas Islam Balitar. Konstruktivisme: Jurnal Pendidikan dan Pembelajaran, 10(2), 154-162.

Wijaya, E. Y., Sudjimat, D. A., \& Nyoto, A. (2016). Transformasi Pendidikan Abad 21 Sebagai Tuntutan Pengembangan Sumber Daya Manusia Di Era Global, 1, 263-278.

Wills, P. (2016). Colour Therapy: An Introductory Guide to The Healing Power of Colour. London: Pavilion Books.

Withrow, R. L. (2004). The Use of Color in Art Therapy. The Journal of Humanistic Counseling, Education and Development, 43(1), 33-40. 